\title{
Association of serum iron and magnesium levels with lipid profile in type 2 diabetic patients
}

\author{
K Ponsuganthi ${ }^{1}$, S Ramya $^{2 *}$
}

${ }^{1}$ Associate Professor, ${ }^{2}$ Assistant Professor, Department of Biochemistry, Annapoorna Medical College and Hospital, Salem, INDIA. Email: drkponsuganthi@gmail.com

Abstract Background: With around 350 million cases in 2014, type 2 diabetes mellitus (T2DM) is one of the most frequent diseases throughout the world. This number is predicted to increase dramatically in the coming years, resulting in serious health and economic challenges. Chronic hyperglycemia found in diabetes mellitus contributes to the development of oxidative stress associated with increased production of reactive oxygen species and lipid peroxidation ${ }^{2}$. Oxidative stress may occur due to changes in plasma and intracellular concentrations of some minerals, such as magnesium and iron ${ }^{3,4}$. As prevalence of DM in India is continuously increasing, present study is designed to explore the association of serum iron and magnesium in Type 2 Diabetes with the fasting sugar and lipid profile and compare it with the controls. Study design: A case-control study includes total of 63 type 2 diabetes mellitus patients and 38 healthy individuals. Fasting blood glucose, lipid profile, iron serum and Magnesium levels were assessed. Results: The present study results showed statistically significant increased serum iron levels and hypomagnesium in type 2 diabetes mellitus patients. Our study shows significant negative association between Serum Magnesium levels with fasting plasma glucose and lipid profile. Serum iron depicted significant positive relation with fasting glucose and lipid profile.

Key Word: serum iron, magnesium levels.

\section{*Address for Correspondence:}

Dr S Ramya, 2Assistant Professor, Department of Biochemistry, Annapoorna Medical College and Hospital, Salem, INDIA.

Email: drramyasathish@gmail.com

Received Date: 06/07/2020 Revised Date: 01/08/2020 Accepted Date: 12/09/2020

DOI: https://doi.org/10.26611/10021532

This work is licensed under a Creative Commons Attribution-NonCommercial 4.0 International License. (cc)) BY-NC

\begin{tabular}{|l|l|}
\hline \multicolumn{2}{|c|}{ Access this article online } \\
\hline Quick Response Code: & Website: \\
& www.medpulse.in \\
\hline & \\
\hline
\end{tabular}

\section{INTRODUCTION}

Diabetes mellitus (DM) refers to a group of common metabolic disorders that share the phenotype of hyperglycemia which is characterized by either deficiency in the secretion or action of insulin or both ${ }^{5}$. Diabetes Mellitus is most common endocrine disease and its metabolic derangement is frequently associated with permanent and irreversible functional and structural changes in the cells of the body. The hyperglycaemic effect enhances the non-enzymatic glycosylation of proteins and accumulation of polyol such as Sorbitol and these end products of the advanced glycosylation, cause irreversible changes and this process culminates in cellular damage which includes long term damage, dysfunction and failure of various organs, eyes, kidneys, nerves and heart and blood vessels. ${ }^{6}$ It has been known that an imbalance of micronutrients participates in the formation of reactive oxygen species and advanced glycation end products. These Oxidative free radicals increase the peroxidation of low-density lipoprotein (LDL) thereby increasing its uptake by macrophages with increased foam cell formation and atherosclerosis, though other mechanisms may exist ${ }^{7}$. Although the mechanism of protein glycoxidation remains unclear, the process is accelerated and potentiated by Reactive Oxygen Species (ROS) under oxidative stress conditions $^{8}$. Iron is a vital mineral for cell homeostasis, which activity is linked to chemical characteristics and oxidation state, with participation in Fenton and HaberWeiss reactions. It has been shown that ROS formation is enhanced by the presence of trace redox-active metals ${ }^{9,10}$. Iron is a strong pro-oxidant and this property, while essential for its metabolic functions, makes iron potentially 
hazardous because of its ability to participate in the generation of powerful oxidant species such as hydroxyl radical. This association of increased level of oxidative stress with high body iron levels can increase the risk of type 2 diabetes mellitus patients ${ }^{11}$. Another important element in glucose metabolism is magnesium. It has a fundamental role in carbohydrate metabolism in general and in Insulin action in particular. Magnesium depletion has a negative impact on glucose homeostasis and insulin sensitivity in patients with type 2 diabetes as well as on the evolution of complications such as retinopathy, arterial atherosclerosis and nephropathy ${ }^{12}$. Reduced Mg levels were also associated with an increased prevalence of arrhythmias in DM2 obese subjects ${ }^{13}$, and with a more rapid decline of renal function. Moreover, hypomagnesemia is currently considered an accurate predictor of progression of diabetic nephropathy ${ }^{14,15}$. Although various elements are closely linked to the progression of diabetes and its co-morbidities, the aim of our study is to ascertain the difference in serum iron and magnesium concentrations and its effect on lipid metabolism between healthy individuals and type 2 diabetes mellitus patients.

Study design and methodology

This was a case-control study conducted at Annapoorna Medical College and Hospital, Salem. The study was approved by the institutional ethical committee. The study group comprised of sixty three previously diagnosed type 2 diabetes mellitus patients as cases and thirty eight age and sex matched apparently healthy individuals as controls. Each individual enrolled in study underwent a detailed history, clinical examination and laboratory examination designed for the study. Subjects with a history of pregnancy and lactation, anemia, those on mineral and iron supplements, drugs like aminoglycosides, amphotericin B, Cetuximab, cyclosporine, digoxin, diuretics and chronic disorders of the liver, kidney, and cardiovascular system, endocrine disorders, established psychiatric disorder and on antidepressant and/or antipsychotic therapy, malignancy were excluded from the study. After obtaining consent from the patient, Venous blood samples were obtained after at least $10 \mathrm{~h}$ of overnight fasting for the estimation of glucose, total cholesterol, triglycerides, HDL, iron, and magnesium and these parameters were estimated using standard kits in Erba EM 200 fully automated clinical chemistry analyser. LDL was calculated by formula. The reference serum magnesium level is $1.3-2.5 \mathrm{mEq} \mid \mathrm{L}$. The reference serum iron level is $60-160 \mu \mathrm{g} / \mathrm{dL}$ and for female $35-145 \mu \mathrm{g} / \mathrm{dL}$. Anthropometric measurements were taken. Body mass index (BMI) was calculated as weight divided by height squared $(\mathrm{kg} / \mathrm{m} 2)$ and waist hip ratio was calculated. Statistical analysis was performed using SPSS version 25. Data were expressed in Mean \pm SD. Statistical tests like independent t-test, and correlation coefficient ' $r$ ' were applied whenever found suitable and necessary. The Pvalue less than 0.05 were considered as significant.

\section{RESULTS AND OBSERVATION}

Table 1 shows that the mean age was $50 \pm 13$ (37-63) years in control group $(n=38)$ and $47 \pm 9(34-71)$ years in type 2 diabetes $(n=63)$ in our study population. The mean body mass index was $25.09 \pm 1.77 \mathrm{~kg} / \mathrm{m} 2$ in control group and $26.01 \pm 1.99 \mathrm{~kg} / \mathrm{m} 2$ in type 2 diabetes patients and BMI of type 2 diabetes patients were found to be more than the controls $(\mathrm{p}<0.001)$. The mean waist hip ratio was $0.91 \pm$ 0.04 in control group and $0.92 \pm 0.14$ in type 2 diabetes patients and there was no statistical significance. Table 1 shows there was a significant rise $(p<0.001)$ of fasting plasma glucose, triglycerides, total cholesterol, and LDLcholesterol in type 2 diabetes patients in comparison with controls. There was no significant fall in HDL-cholesterol in type 2 diabetes than controls. Table 2 shows that the serum iron was significantly high in type 2 diabetes patients when compare to control group and table 3 shows significant positive correlation of serum iron with fasting glucose, cholesterol, triglycerides and LDL-c. However, the concentrations of serum iron in this study were within the recommended normal values in both groups. And also table 2 shows that the serum magnesium was found to be significantly lower in type 2 diabetes patients than controls and table 3 shows there was a significant negative correlation between serum magnesium with fasting blood glucose and lipid parameters in type 2 diabetes patients when compared to control group

\begin{tabular}{ccccc}
\multicolumn{5}{c}{ Table 1: Demographic and clinical characteristics of the study population } \\
\hline $\begin{array}{c}\text { Control } n=38 \\
\text { Mean } \pm \text { SD }\end{array}$ & $\begin{array}{c}\text { Cases } n=63 \\
\text { Mean } \pm \text { SD }\end{array}$ & t-test & p-value \\
& $50 \pm 13$ & $47 \pm 9$ & 1.126 & 0.26 \\
Age & $25.09 \pm 1.77$ & $26.01 \pm 1.99$ & -2.345 & $<0.05$ \\
BMI & $0.91 \pm 0.04$ & $0.92 \pm 0.14$ & -0.386 & 0.71 \\
WHR & $84.45 \pm 9.26$ & $146.21 \pm 42.27$ & -8.862 & $<0.001$ \\
GLU-F & $180.05 \pm 33.22$ & $256.60 \pm 53.69$ & -7.913 & $<0.001$ \\
Cho & $176.16 \pm 80.26$ & $241.30 \pm 71.73$ & -4.227 & $<0.001$ \\
TGL & $123.18 \pm 19.86$ & $167.933 \pm 43.21$ & -7.345 & $<0.001$ \\
LDL & $41.45 \pm 5.10$ & $43.22 \pm 9.39$ & -1.071 & 0.28 \\
HDL & & &
\end{tabular}




\begin{tabular}{|c|c|c|c|c|}
\hline Parameters & $\begin{array}{c}\text { Control } n=38 \\
\text { Mean } \pm \text { SD }\end{array}$ & $\begin{array}{l}\text { Cases } n=63 \\
\text { Mean } \pm S D\end{array}$ & t-test & p-value \\
\hline $\mathrm{Fe}$ & $98.05 \pm 24.31$ & 139.9424 .38 & \pm-8.371 & $<0.001$ \\
\hline $\mathrm{Mg}$ & $1.829 \pm 0.4368$ & 1.3590 .5104 & \pm 4.728 & $<0.001$ \\
\hline
\end{tabular}

Table 3: Pearson's correlation between serum iron and magnesium with fasting glucose and lipid profile in type 2 diabetes patients and control groups

\begin{tabular}{|c|c|c|c|c|}
\hline \multirow[t]{2}{*}{ Parameters } & \multicolumn{2}{|c|}{ Serum iron $(\mu \mathrm{g} / \mathrm{dL})$} & \multicolumn{2}{|c|}{$\begin{array}{c}\text { Serum magnesium } \\
(\mu \mathrm{g} / \mathrm{dL})\end{array}$} \\
\hline & Control & cases & Control & cases \\
\hline \multicolumn{5}{|c|}{ Fasting Glucose } \\
\hline$r$ & .032 & $0.288^{* *}$ & -.176 & $-.033^{*}$ \\
\hline $\mathrm{p}$ & .850 & .001 & .292 & .019 \\
\hline \multicolumn{5}{|c|}{ Total Cholesterol } \\
\hline$r$ & .059 & $0.343^{* *}$ & -.217 & $-.219^{* *}$ \\
\hline$p$ & .727 & .001 & .192 & .025 \\
\hline \multicolumn{5}{|l|}{ Triglycerides } \\
\hline r & .032 & $.253^{* *}$ & -.052 & $-.293^{* *}$ \\
\hline \multirow[t]{2}{*}{$\mathrm{p}$} & .850 & .015 & .755 & .018 \\
\hline & & HDL-C & & \\
\hline$r$ & -.128 & -.046 & .157 & .120 \\
\hline \multirow[t]{2}{*}{$p$} & .444 & .783 & .345 & .351 \\
\hline & & LDL-C & & \\
\hline$r$ & .255 & $.344^{* *}$ & -.279 & $-.247^{*}$ \\
\hline $\mathrm{p}$ & .122 & .006 & 089 & .013 \\
\hline
\end{tabular}

\section{DISCUSSION}

Diabetes Mellitus (DM), a major global health issue which not only decrease life quality and expectancy, but are also becoming a problem regarding the financial burden for health care systems ${ }^{16}$. Therefore every effort should be made to reduce the diabetes burden. Glucose, in the presence of reactive oxygen species (ROS), acts as an as an oxidative agent and drives deleterious processes in Diabetes Mellitus. And also the formation of reactive oxygen species (ROS) is an inevitable by product of metabolism. Oxidative stress induced by an abundance of ROS or failure in the anti oxidative machinery, is the cause of much pathology. Moreover, Lipid oxidation is a major harmful consequence of ROS formation, as it reflects irreversible oxidative changes of membranes ${ }^{17,}{ }^{18}$. Although there are various causes for the ROS formation and oxidative stress, it may occur due to changes in plasma and intracellular concentrations of some minerals, such as magnesium and iron ${ }^{3,4}$. In this present study we have observed a statistically significant frequency of increased serum iron in the type 2 diabetic patients when compared to the controls. However, the concentrations of serum iron in this study were within the recommended normal values in both groups, but serum iron was significantly increased in the diabetic subjects when compared to control group. In addition to this, there is significant positive correlation with serum iron with total cholesterol, triglycerides and
LDL-cholesterol in type 2 diabetic patients whereas it is not correlating with HDL-cholesterol in our study population. Although the exact molecular mechanism of iron-related pathology in diabetes and dyslipidemia is not yet clearly understood, many studies have shown that an ability of iron to induce oxidative stress and inflammation is likely to be involved in the pathogenesis ${ }^{19-23}$. Iron in excess increases lipid peroxidation that modifies fatty acid profile of the cellular membranes leading to damages of organelles and mitochondrial dysfunction ${ }^{24,25}$. This finding is consistent with a Study done by Grotto which shown that high iron levels induce the production of free radicals which promote DNA damage and interact with unsaturated fatty acids, inducing lipid peroxidation ${ }^{26}$. As shown by Jiang Li et al. that serum ferritin levels are significantly associated with lipid parameters, independent of glucose metabolism disorders and components of metabolic syndrome (MetS) ${ }^{27}$. In this present study we observed a statistically significant hypomagnesemia in the type 2 diabetic patients when compared to the control groups. Hypomagnesemia is a common observation in studies assessing patients with type 2 diabetes ${ }^{28,29}$. And as shown by Fabiane et al. that reduced plasma levels of magnesium in patients with type 2 diabetes appears to be one of the factors involving diabetes pathophysiology ${ }^{30}$. In the present study we have also observed that there was negative correlation of serum magnesium with fasting 
glucose, total cholesterol, triglycerides and LDLcholesterol. This finding is consistent with study done by Dong et al., recent meta-analysis of 13 prospective cohort studies involving 536,318 participants and 24,516 cases; it has clearly indicated the inverse association between $\mathrm{Mg}$ intake and T2D risk ${ }^{31}$. Some mechanisms have been proposed to clarify the relationship between magnesium deficiency and iron metabolism in patients with type 2 diabetes. Accordingly, results of some studies suggest that magnesium deficiency is involved in the induction of hemolysis, contributing to iron release which is, in turn, a pro-oxidant nutrient enhancing the production of reactive oxygen species and the synthesis of inflammatory markers ${ }^{32,33}$. At normal levels, magnesium is described to have a protective effect on damage caused by iron overload, reducing hemolysis and the release of free iron ${ }^{33}$. Inverse correlations between erythrocyte magnesium and plasma iron and ferritin in diabetic patients may indicate mechanisms triggered by the body to protect diabetic patients from increased iron levels and to prevent a more vulnerable oxidative state which could promote changes and damage. Similarly, it has been reported that reduced erythrocyte magnesium levels are associated with increased iron in several tissues ${ }^{33}$, and low dietary intake of magnesium in rats induces increased iron absorption and reduced number of red blood cells ${ }^{32}$. Animal experiments found that $\mathrm{Mg}$ deficiency was associated with reduced glucose uptake and utilization in insulin-sensitive tissues, thus promoting insulin resistance and the development of diabetes $^{34,35}$. Furthermore, randomized controlled trials including non-diabetic individuals found improvement in insulin sensitivity together with increased levels of serum $\mathrm{Mg}$ after Mg supplementation ${ }^{36}$.

\section{CONCLUSION}

The present study results provide evidence that increased serum iron levels and hypomagnesium were significantly associated with fasting glucose and dyslipidemia in type 2 diabetes patients. Further studies, especially well-designed observational and cohort studies and randomized trials, are warranted to provide stronger evidence and establish a causal inference.

\section{REFERENCES}

1. International Diabetes Federation. IDF Diabetes Atlas Update Poster, 6th ed.; International Diabetes Federation: Brussels, Belgium, 2014.

2. Shams MEE, Al-Gayyar MMH, Barakat EA. Type 2 diabetes mellitus-induced hyperglycemia in patients with NAFLD and normal LFTs: relationship to lipid profile, oxidative stress and pro-inflammatory cytokines. Sci Pharm 2011;79:623-34.

3. Shah NC, Liu JP, Iqbal J, Hussain M, Jiang XC, Li Z et al.. $\mathrm{Mg}$ deficiency results in modulation of serum lipids, glutathione, and NO synthase isozyme activation in cardiovascular tissues: relevance to de novo synthesis of ceramide, serum $\mathrm{Mg}$ and atherogenesis. Int $\mathrm{J}$ Clin Exp Med 2011;4(2):103-18.

4. Sanchez-Morito N, Planells E, Aranda P, Llopis J. Influence ofmagnesium deficiency on the bioavailability and tissue distributionof iron in the rat. J Nutr Biochem 2000;11:103-8.

5. Classification and Diagnosis of Diabetes. Diabetes Care 2014;38 (Suppl 1):S8-16.

6. Bennett PH,Knowler WC; Joslin's Diabetes Mellitus. Defination,Diagnosis and Classification of Diabetes Mellitus and Glucose Homeostasis. 14th edition, Boston: Joslin Diabetes Center, 2005.

7. Steinberg D. Anti-oxidant vitamins and coronary heart disease. N Engl J Med. 1993; 328: 1487-1489

8. J.W. Baynes, S.R. Thorpe, Role of Oxidative Stress in Diabetic Complications, Diabetes. 48 (1999) 1-9.

9. K. Jomova, D. Vondrakova, M. Lawson, M. Valko, Metals, oxidative stress and neurodegenerative disorders, Molecular and cellular biochemistry. 345 (2010) 91-104.

10. E.R. Stadtman, R.L. Levine, Free radical-mediated oxidation of free amino acids and amino acid residues in proteins, Amino acids. 25 (2003) 207-218.

11. Dongiovanni, P.; Ruscica, M.; Rametta, R.; Recalcati, S.; Ste

ani, L.; Gatti, S.; Girelli, D.; Cairo, G.; Magni, P.; Fargion, S.; et al. . Dietary Iron Overload Induces Visceral Adipose Tissue Insulin Resistance. Am. J. Pathol. 2013, 182, 22542263.

12. Grafton G, Baxter MA, Sheppard MC; Effects of magnesium on sodium dependent inositol transport. Diabetes, 1992;41:35-3

13. Del Gobbo LC, Song Y, Poirier P, Dewailly E, Elin RJ, Egeland GM. Low serum magnesium concentrations are associated with a high prevalence of premature ventricular complexes in obese adults with type 2 diabetes. Cardiovasc Diabetol 2012; 11: 23 [PMID: 22405520 DOI: 10.1186/1475-2840-11-23].

14. Sakaguchi Y, Shoji T, Hayashi T, Suzuki A, Shimizu M,Mitsumoto K, Kawabata H, Niihata K, Okada N, Isaka Y, Rakugi H, Tsubakihara Y. Hypomagnesemia in type 2 diabetic nephropathy: a novel predictor of end-stage renal disease. Diabetes Care 2012; 35: 1591-1597 [PMID: 22498805 DOI: $10.2337 / \mathrm{dc12-0226]}$

15. Tin A, Grams ME, Maruthur NM, Astor BC, Couper D, Mosley TH, Selvin E, Coresh J, Kao WH. Results from the Atherosclerosis Risk in Communities study suggest that low serum magnesium is associated with incident kidney disease. Kidney Int 2015; 87: 820-827 [PMID: 25272232 DOI: 10.1038/ki.2014.331]

16. I.D. Federation, DIABETES ATLAS, International Diabetes Federation, 2015.

17. Lucas DT, Szweda LI. Cardiac reperfusion injury: aging, lipid peroxidation, and mitochondrial dysfunction. Proc Natl Acad Sci U S A 1998;95:510-4.

18. Ambrosio G, Flaherty JT, Duilio C, Tritto I, Santoro G, Elia PP, et al. . Oxygen radicals generated at reflow induce peroxidation of membrane lipids in reperfused hearts. $\mathrm{J}$ Clin Invest 1991;87:2056-66

19. Weinberg, E. D. (1990) Cellular iron metabolism in health and disease. Drug Metab. Rev. 22: 531-579. 
20. Crawford, R. D. (1995) Proposed role for a combination of citric acid and ascorbic acid in the production of dietary iron overload: a fundamental cause of disease. Biochem. Mol. Med. 54: 1-11.

21. Talaei M, Wang YL, Yuan JM, Pan A, Koh WP (2017) Meat, dietary heme iron and risk of type 2 diabetes: The Singapore Chinese Health Study. Am J Epidemiol 186: 824-833.

22. Kim CH, Kim HK, Bae SJ, Park JY, Lee KU, et al. . (2011) Association of elevated serum ferritin concentration with insulin resistance and impaired glucose metabolism in Korean men and women.. Metabolism 60: 414-420.

23. Eshak ES, Iso H, Maruyama K, Muraki I, Tamakoshi A (2017) Associationsbetween dietary intakes of iron, copper and zinc with risk of type 2 diabetes mellitus: A large population-based prospective cohort study. Clin Nutr.

24. Seo AY, Xu J, Servais S, Hofer T, Marzetti E, et al.. (2008) Mitochondrial iron accumulation with age and functional consequences. Aging Cell 7:706-716.

25. Britton RS, Bacon BR, Recknagel RO (1987) Lipid peroxidation and associate hepatic organelle dysfunction in iron overload. Chem Phys Lipids 45: 207-239.

26. Grotto HZW. Iron metabolism: an overview on the main mechanisms involved in its homeostasis. Rev Bras Hematol Hemoter 2008;30(5):390-7.

27. Jiang Li, Weimin Bao, Tie Zhang, Yun Zhou, Hui Yang, Hongbing Jia, Rui Wang, Yongtong Cao, Cheng Xiao. Independent relationship between serum ferritin levels and dyslipidemia in Chinese adults: A population study

28. Sales CH, Pedrosa LFC, Lima JG, Lemos TMAM, Colli C.Influence of magnesium status and magnesium intake on the blood glucose control in patients with type 2 diabetes. Clin Nutr 2011;30(3):359-64.
29. Pham PC, Pham PM, Pham PT, Pham SV, Pham PA, Pham PT. The link between lower serum magnesium and kidney function in patients with diabetes mellitus type 2 deserves a closer look. Clin Nephrol 2009;71(4):375-9.

30. Fabiane Araújo Sampaio, Mayara Monte Feitosa, Cristiane Hermes Sales,Danilla Michelle Costa e Silva, Kyria Jayanne Clímaco Cruz, Francisco Erasmo Oliveira,Célia Colli and Dilina do Nascimento Marreiro. Influence of magnesium on biochemical parameters of iron and oxidative stress in patients with type 2 diabetes. Nutr Hosp. 2014;30(3):570-576.

31. Dong JY, Xun P, He K, Qin LQ (2011) Magnesium intake and risk of type 2 diabetes: meta-analysis of prospective cohort studies. Diabetes Care 34: 2116-2122.

32. Sanchez-Morito N, Planells E, Aranda P, Llopis J. Influence of magnesium deficiency on the bioavailability and tissue distribution of iron in the rat. J Nutr Biochem 2000;11:103-8.

33. Shi ZM, Hu XS, Yuan BJ, Gibson R, Dai Y, Garg M. Association between magnesium: iron intake ratio and diabetes in Chinese adults in Jiangsu Province. Diabet Med 2008;25(10):1164-70.

34. Ford ES. Serum magnesium and ischaemic heart disease: findings from a national sample of US adults. Int $\mathrm{J}$ Epidemiol. 1999;28:645-51.

35. Balon TW, Gu JL, Tokuyama Y, Jasman AP, Nadler JL. Magnesium supplementation reduces development of diabetes in a rat model of spontaneous NIDDM. Am J Phys. 1995;269:E745-52.

36. Rodriguez-Moran M, Guerrero-Romero F. Oral magnesium supplementation improves the metabolic profile of metabolically obese, normal-weight individuals: a randomized double-blind placebo-controlled trial. Arch Med Res. 2014;45:388-93.

\section{Source of Support: None Declared} Conflict of Interest: None Declared 